\title{
ANKYLOSING SPONDYLITIS IN CHILDREN AND ADOLESCENTS
}

\author{
BY \\ PHILIP JACOBS \\ From the Royal Orthopaedic Hospital, Birmingham
}

(RECEIVED FOR PUBLICATION FEBRUARY 28, 1963)

Ankylosing spondylitis is a disease that usually affects young men, though older men and both young and middle-aged women may suffer from the condition. Close questioning of patients will often elicit a previous history of fleeting joint pains, 'growing pains' and pains low in the back and down the thighs - such symptoms may have been of several years' duration. To Scott (1942) is due the credit for this observation. He recorded cases whose symptoms could be traced back to childhood and he named this stage of the illness 'the prespondylitic syndrome'. He further stated that on account of the wandering nature of the pains, most of such patients have been erroneously treated for months or years for such conditions as recurrent fibrositis, muscular rheumatism or even just growing pains.

More recently other authors have confirmed Scott's (1942) observations. Hart (1955) reported that 18 out of 166 male and two out of 18 female patients suffering from established ankylosing spondylitis complained of symptoms beginning between the ages of 10 and 15 years. Edström, Thune and Wittbom-Cigén (1960) recorded three boys in whom ankylosing spondylitis started at the ages of 5, 8 and 12 years. Ansell and Bywaters (1962) followed up 43 children who were regarded initially as probably but not definitely suffering from Still's disease. Two of these children developed ankylosing spondylitis, their ages at the onset of symptoms were 10 and 12 years; their sex was not recorded.

Though it is true that the possibility of such an early onset of ankylosing spondylitis is becoming increasingly recognized, it is felt that this is not widely known. Due to the indefinite symptomatology and particular age incidence, these patients may seek help from a wide variety of practitioners such as general physicians, paediatricians, rheumatologists and orthopaedic surgeons. Others may remain for years under the care of their general practitioners.

In this paper, three cases are presented whose initial symptoms dated from the ages of 10,11 and 15 years, and over the years the development of the classical picture of ankylosing spondylitis was observed. Problems of the diagnosis are discussed with special reference to radiological findings.

\section{Case Histories}

Case 1. A girl, who was born on January 26, 1944, attended hospital on March 15, 1955, complaining of pain in the right hip. The pain was of four months' duration; thus she dated her symptoms to the age of $10 \frac{3}{4}$ years. The pain prevented her from running fast and from skipping.

On examination, movements of the right hip were painful and restricted. No other abnormal clinical finding was discovered.

From a radiograph, March 15, 1955 (Fig. 1), anteroposterior view of the hips, it was thought that there was some acetabular protrusion on both sides. No further lesion was noted, but in retrospect one sees some sclerosis round the right sacro-iliac joint and also slight similar changes on the left side.

Having experienced alternating remissions and exacerbations of symptoms for the following nine months, she was admitted to hospital with a tentative diagnosis of protrusio acetabuli. She was treated on traction for three months. Her erythrocyte sedimentation rate (Westergren) was raised at one time to $23 \mathrm{~mm}$./ hr., but it subsequently became normal. She became asymptomatic after three months and remained well for the next three years apart from minor exacerbations of low back pain and pain in both hips.

A radiograph on February 25, 1958 (Fig. 2) showed irregularity of margins of the right sacro-iliac joint and some peri-articular sclerosis.

On December 13, 1960, she complained that exacerbations of pains had become more severe. At this time, though still attending school, she worked on Saturdays filling self-service trays in a supermarket. She complained of pains in both hips after doing this work. 


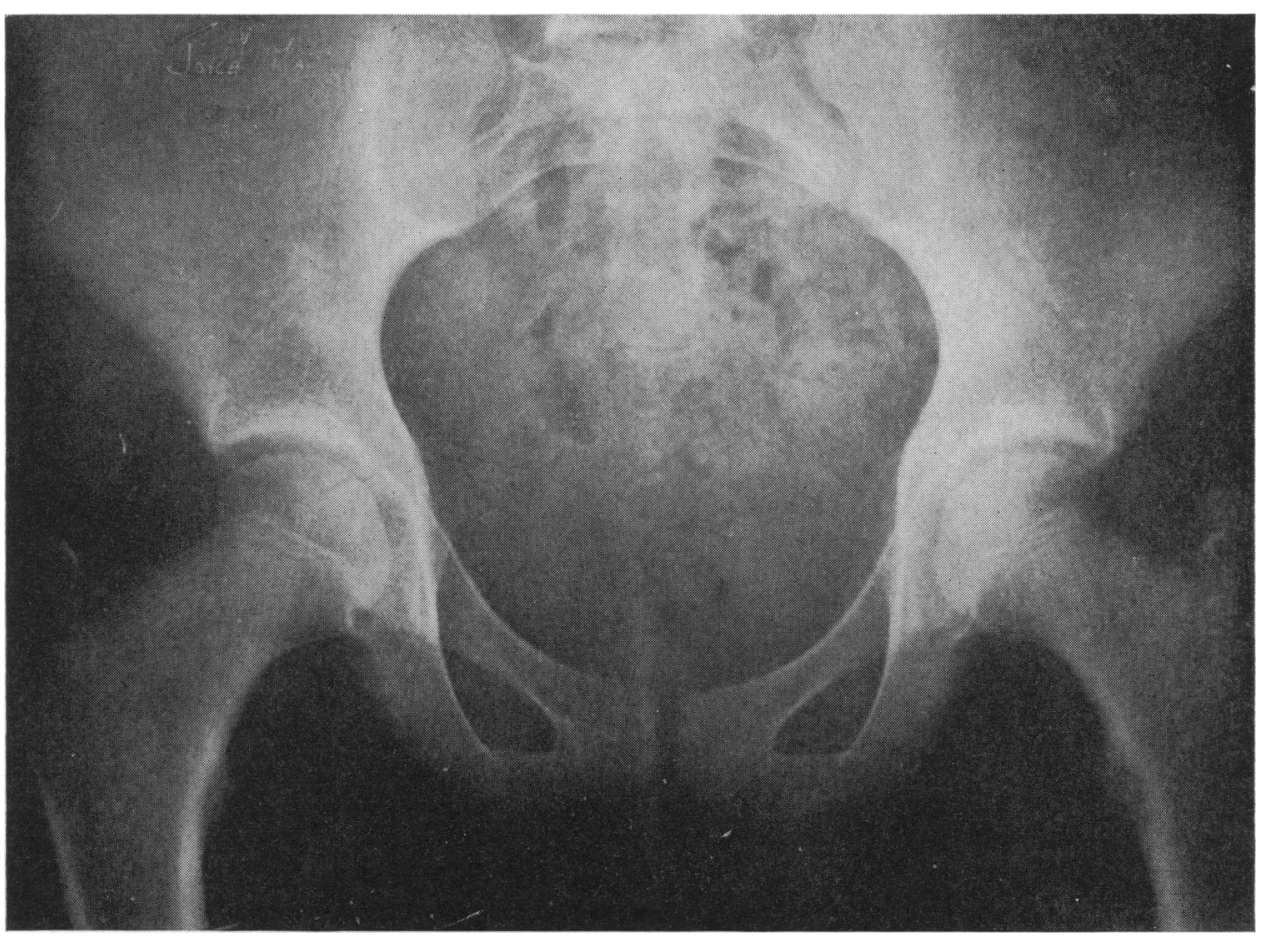

Fig. 1.-Case 1, March 15, 1955, antero-posterior view of the hips. The sacro-iliac joints were considered to be normal at the time. However, some sclerosis is seen round the right sacro-iliac joint and there is minimal sclerosis round the left sacro-iliac joint.

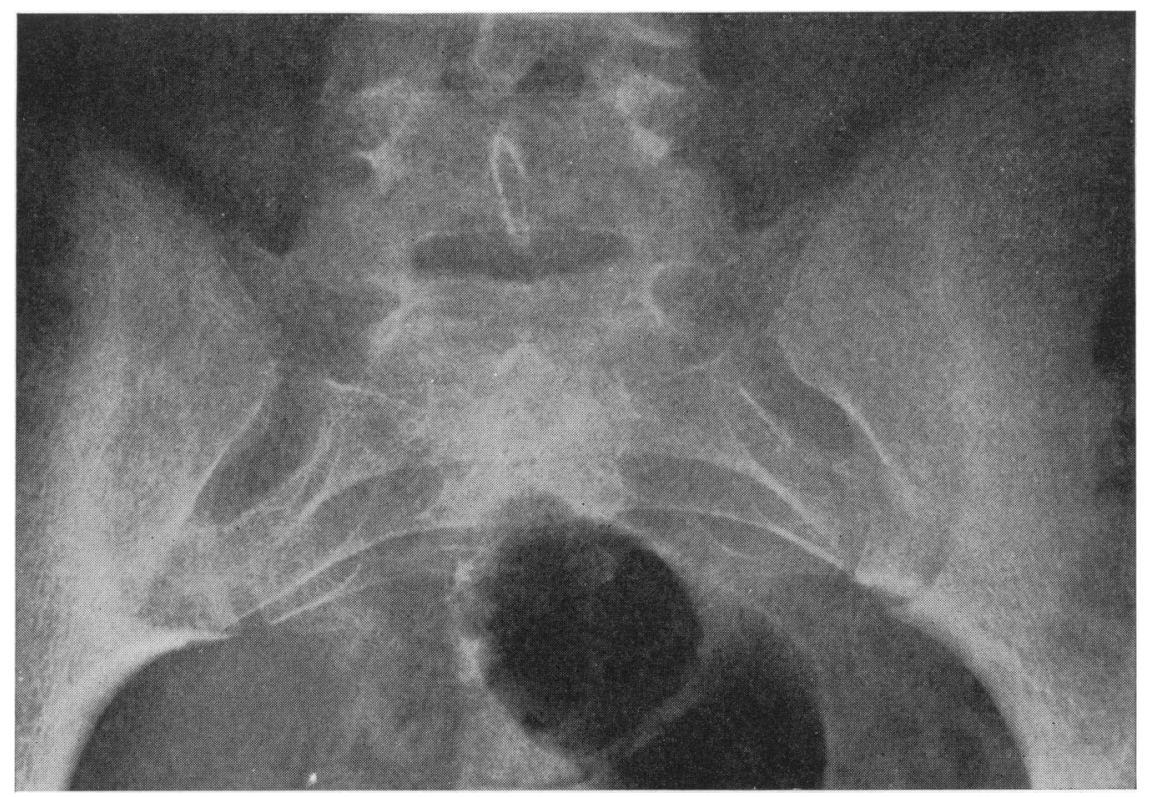

FIG. 2.-Case 1, February 25, 1958, antero-posterior view of sacro-iliac joints showing development of ankylosing spondylitis. The patient is now $14 \frac{1}{12}$ years. Irregularity of the right sacro-iliac joint margins and reduction of joint space on the left side are shown. 


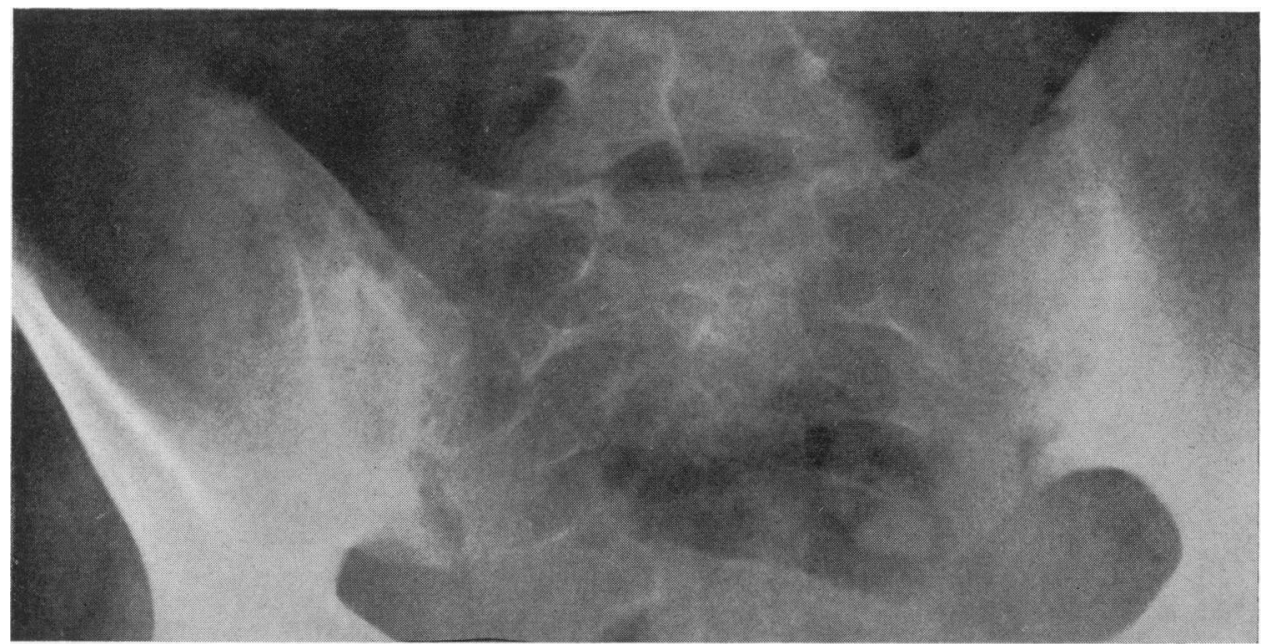

Fig. 3.-Case 1, January 4, 1961, postero-anterior view of sacro-iliac joints. Marginal erosions and peri-articular sclerosis are seen on both sides and there is reduction of joint space on the left side.

Considerable stiffness in the lumbar spine was noted though movements of the hip joints were full. Her erythrocyte sedimentation rate was $36 \mathrm{~mm}$./hr. She was considered clinically to be suffering from ankylosing spondylitis.

A radiograph on January 4, 1961 (Fig. 3) showed definite erosions of both sacro-iliac joints and also some peri-articular sclerosis. No radiological abnormality was found in the hips or in the spine.

The lesion progressed for a while, her erythrocyte sedimentation rate remained high and general stiffness of the spine developed.

A radiograph on October 13, 1962 (Fig. 4) revealed that the left sacro-iliac joint was completely ankylosed and the right one almost so.

Comments. (a) The history of pains, first involving one side then the other with remissions, is typical of the pre-spondylitic stage of ankylosing spondylitis.

(b) The disease in this girl started at the age of 10 years and was fully developed before the age of 17 years.

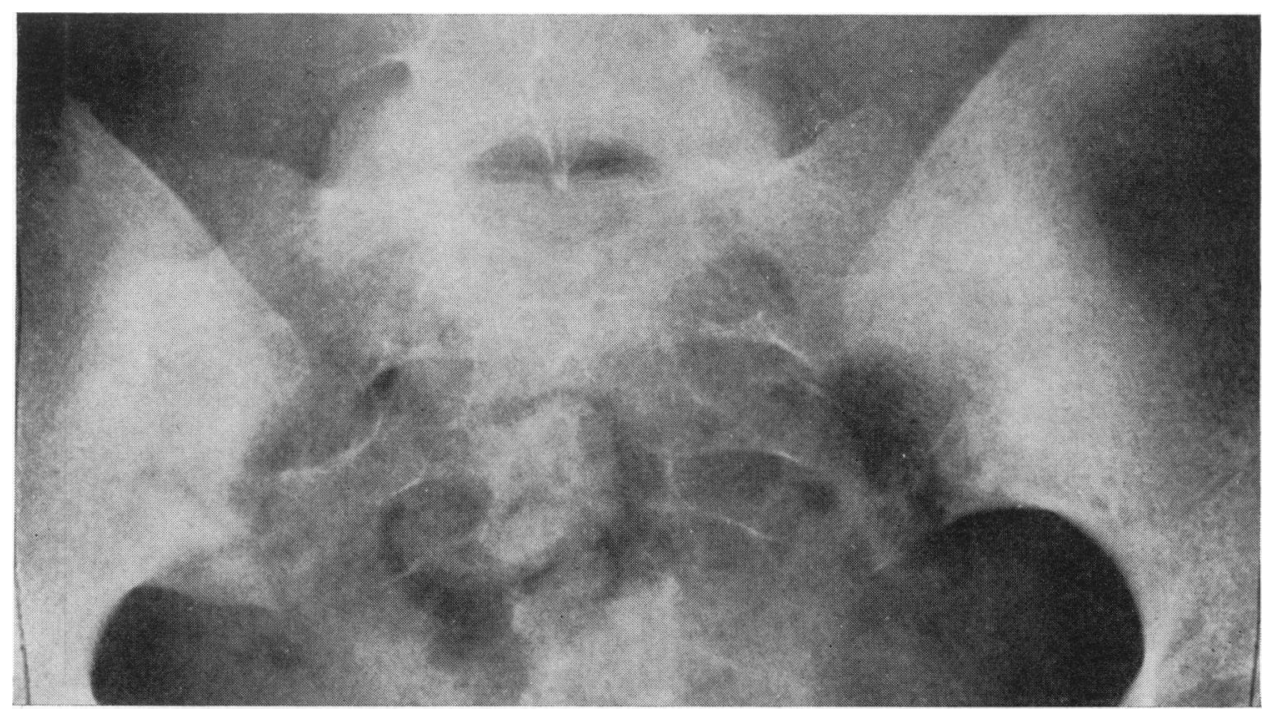

Fig. 4.-Case 1, October 13, 1962, the left sacro-iliac joint is now completely ankylosed and the right one almost so. 


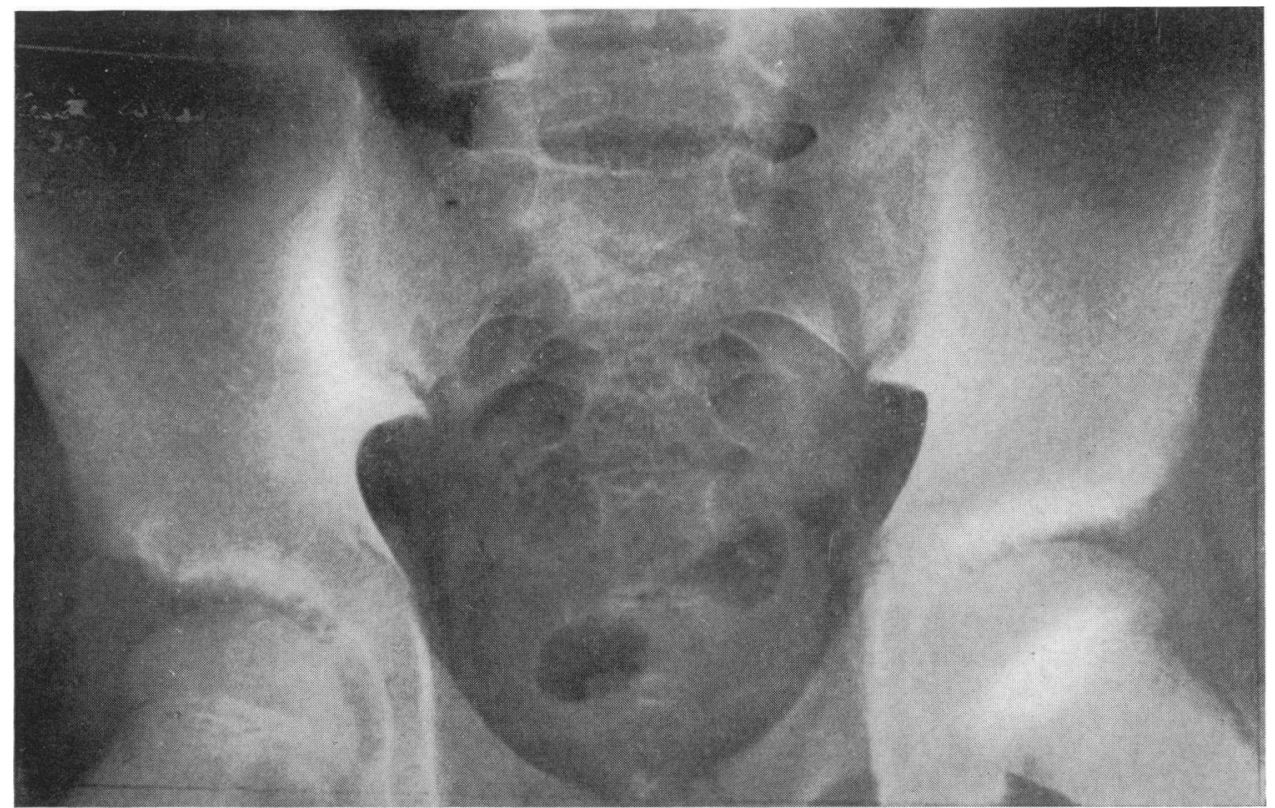

Fig. 5.-Case 2, August 23, 1957, antero-posterior view of the pelvis. Left-sided sacralization of L5 is noted. Sclerosis is seen round both sacro-iliac joints, more pronounced on the right side. The sclerosis was thought, incorrectly, to be associated with the sacralized 5th lumbar vertebra.

(c) Some sclerosis round the right sacro-iliac joint and a little round the left one was seen on the initial and all subsequent radiographs. Though this appearance is not in itself pathognomonic of ankylosing spondylitis, it is felt that one should have paid more attention to it.

Case 2. A boy, whose date of birth was September 15, 1944, first attended hospital on August 23, 1957, on account of intermittent pain and limp in the right hip and discomfort in the region of the right sacro-iliac joint. He dated his symptoms to an injury at physical training 18 months previously; ever since that time he had suffered from intermittent attacks of pain. Limited abduction of the right hip was found on examination, but there was no other abnormal physical sign.

A radiograph on August 23, 1957 (Fig. 5), showed a left-sided sacralization of L5. Some sclerosis was seen round the right sacro-iliac joint and a little round the left sacro-iliac joint. It was thought that the sclerosis round the sacro-iliac joints was secondary to the anomaly of the lumbo-sacral region.

He became symptom free after three months, and no abnormal physical signs were found.

He attended hospital next on January 26, 1962, complaining of pain and stiffness, which was now more severe, in the left hip and in the left knee. In the intervening years he had experienced only transient pains which had not inconvenienced him. Now the pains had become sufficiently troublesome to interfere with his work as a butcher. Definite clinical signs of ankylosing spondylitis were present now; his back was flat due to muscle spasm, movements of the spine and hips were restricted. His erythrocyte sedimentation rate was $40 \mathrm{~mm}$./hr. and his Rose-Waaler test was negative.

A radiograph on January 26, 1962 (Fig. 6) showed now much dense sclerosis round both sacro-iliac joints with sub-articular erosions. No radiographic evidence of spinal lesions was demonstrable.

Comments. (a) Earliest symptoms in this boy were noted at the age of 11 years, and he attended hospital before his 13th birthday.

(b) A very similar history to that of Case 1 was given, including asymmetrical development of the lesion.

(c) Early sclerosis round sacro-iliac joints was incorrectly attributed to the presence of an anomaly of the lumbo-sacral spine.

Case 3. A girl, who was born on August 16, 1936, was first seen on July 17, 1952, with a history of pain in the lower part of the back, over the right sacro-iliac joint and down the right leg. She dated her symptoms to a fall some three months previously, but it seemed that pains in the back caused her to fall. Fleeting pains in the lower part of the back had been noted for some months previously.

There was definite pain on compression of the right sacro-iliac joint and some pain and restricted movement in the right hip. A clinical diagnosis of tuberculosis of the right sacro-iliac joint was made. At the time, there was considered to be supporting radiographic evidence for the diagnosis, but on later scrutiny no definite radiological abnormality could be found. She was treated in a plaster spica for three months and then discharged home wearing a spinal support. It was considered that 


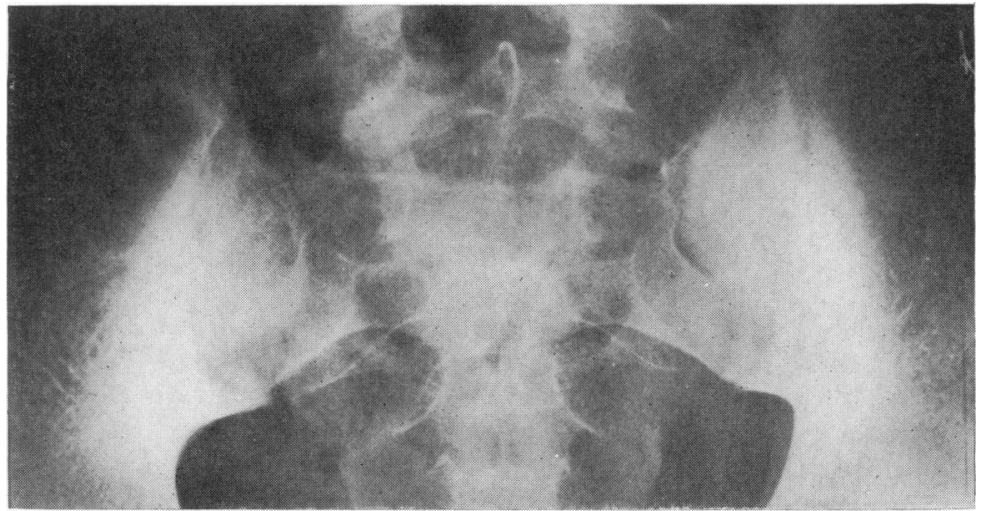

Fig. 6.-Case 2, January 26, 1962. There is now much dense sclerosis round both sacro-iliac joints, reduction of joint spaces and periarticular erosions.

no definite clinical or radiographic evidence of a tuberculous lesion had been substantiated and a final diagnosis of sacro-iliac strain was suggested.

She remained in good general health for the next two and a half years, merely complaining of fleeting pains in the lower part of the back and in the right sacro-iliac region. No disability was caused and she started nursing.

Soon after her 18th birthday, she complained of severe pain in the right sacro-iliac joint and also of pain in the left sacro-iliac joint, in both hips and in the spine. Her erythrocyte sedimentation rate was now $40 \mathrm{~mm} . / \mathrm{hr}$.
A radiograph on February 17, 1956 (Fig. 7) showed dense peri-articular sclerosis round both sacro-iliac joints and sub-articular erosions. No spinal lesions were found at this stage.

In view of the rather nebulous previous history of a possible tuberculous sacro-iliitis, a biopsy of bone round the right sacro-iliac joint was performed. This procedure ruled out the possibility of a tuberculous lesion.

Symptoms progressed rapidly and severe pains and very restricted movements of the hips and spine were experienced. Her erythrocyte sedimentation rate was

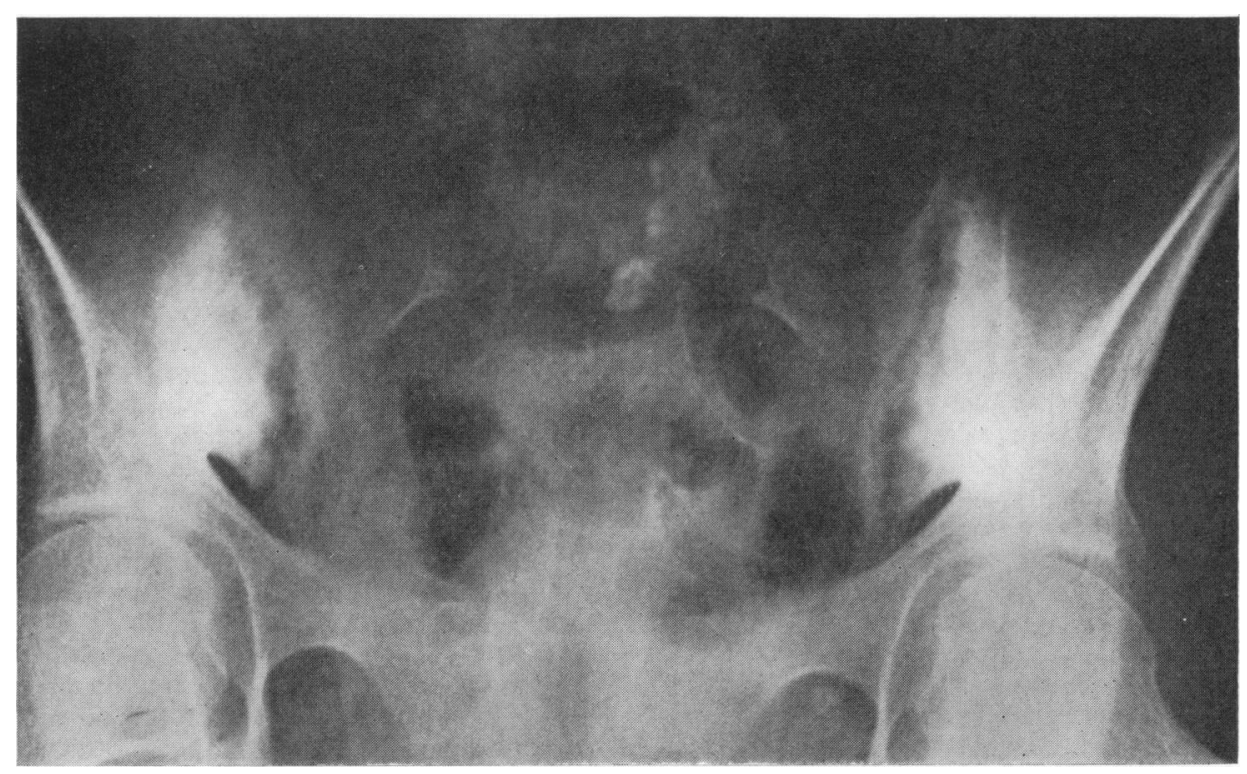

Fig. 7.-Case 3, February 17, 1956, postero-anterior view of the sacro-iliac joints. There are fully-developed changes of ankylosing spondylitis manifested by dense peri-articular sclerosis and marginal erosions. 


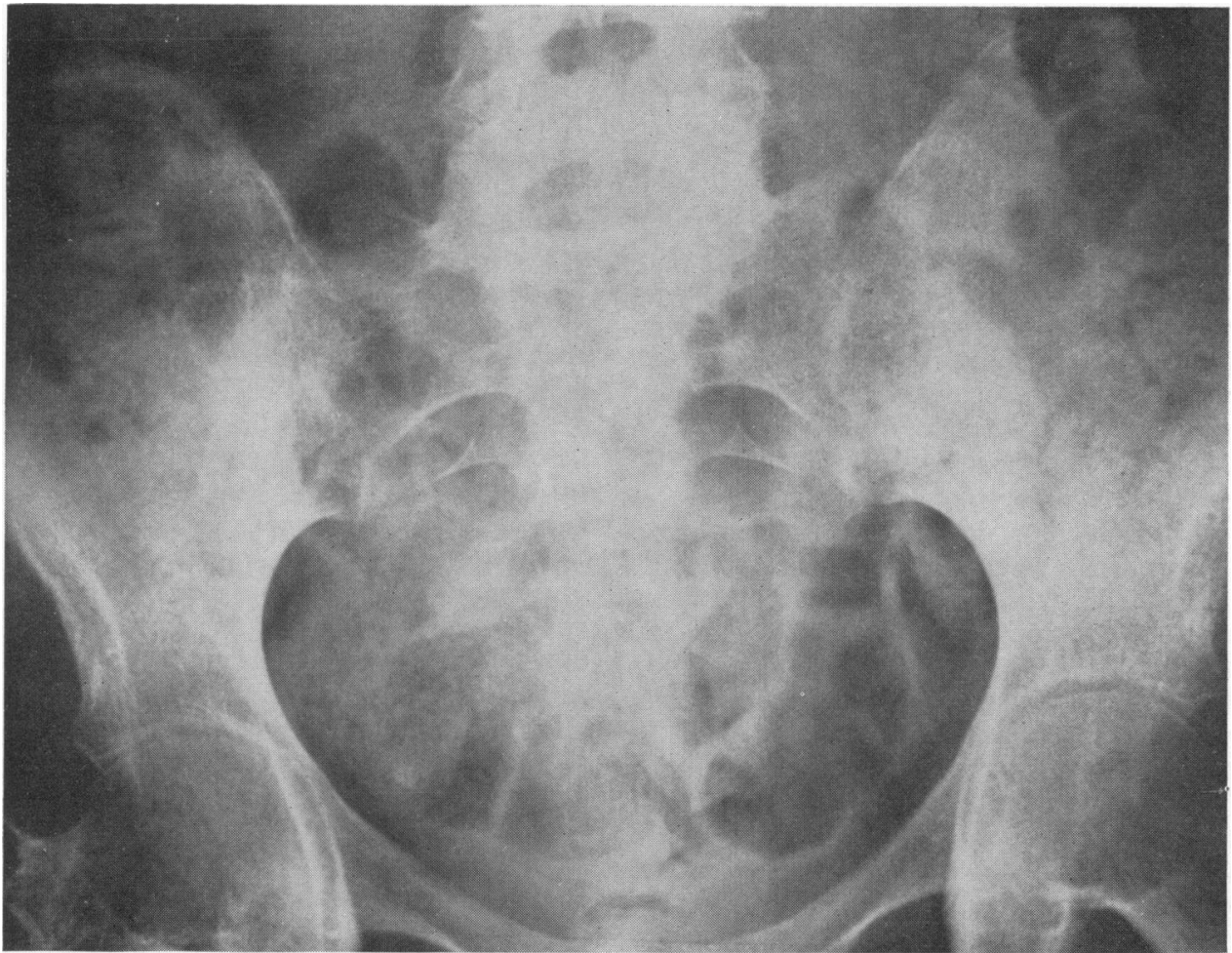

Fig. 8.-Case 3, October 4, 1956, antero-posterior view of the pelvis. Marked progression of the lesion is seen. The sacro-iliac joints are almos fused and considerable loss of cartilage in both hips has now resulted.

constantly raised. There was no doubt now of the diagnosis of ankylosing spondylitis.

A radiograph on October 4, 1956 (Fig. 8) revealed deterioration. The sacro-iliac joints were almost completely fused and considerable loss of joint cartilage was seen in both hips.

Comments. (a) This girl's initial history of fleeting pains first on one side and then on both was very similar to that of Cases 1 and 2.

(b) Difficulties in diagnosis arose even when both sacro-iliac joints were affected. In retrospect, my error was due first to being misled by the previous history of a possible tuberculous lesion and, more important, due to unfamiliarity with the possibility of a pre-spondylitic stage of ankylosing spondylitis in a 15-year-old girl.

\section{Discussion}

The diagnosis of ankylosing spondylitis in its fully developed form is usually obvious at first sight, both clinically and radiologically. In the early stages of the disease, however, the converse often applies and a definitive diagnosis of ankylosing spondylitis may be impossible to reach either clinically or radiologically, even though the condition may be strongly suspected.
Factors of importance in considering the diagnosis are:

(a) Sex incidence: ankylosing spondylitis occurs more frequently in male subjects. The sex incidence is variously stated but is usually of the order of 10 men to one woman. Consideration of the sex incidence is not likely to be of help in a difficult case, indeed two of the present cases reported were female.

(b) Natural history of the disease: West (1949) has described three phases of the disease. (1) repeated attacks of pain and stiffness-this phase corresponds with the pre-spondylitic syndrome of Scott (1942); (2) florid phase of continuous symptoms and general illness; (3) a stage of declining activity and minor relapses.

The three cases described fit in well with the first two phases. Only Case 3 has been followed to the third phase.

Childhood cases will, of course, be in the first phase. It seems that a relatively latent period of several years may elapse before the second phase is reached. Then the disease pursues a rapid course clinically and radiologically. 
(c) Symmetry of the sacro-iliac joint changes: usually in ankylosing spondylitis the sacro-iliac joint changes are bilateral and symmetrical. In the first phase one side only may be involved or both sides at different times may be stiff and painful.

The established lesion is not necessarily symmetrical, however. Scott (1942) recognized that ankylosing spondylitis may manifest itself radiologically as a unilateral sacro-iliitis. Grainger (1957) recorded and illustrated two further examples. In these cases, the opposite sacro-iliac joint will eventually be affected but the asymmetrical pattern may persist throughout the course of the disease.

(d) Radiology: in the absence of a specific biochemical test, the radiological diagnosis of ankylosing spondylitis is of prime importance. Before considering pathological changes, it is important to understand the normal structural difference between the sacro-iliac joints of adolescence and and adult life. The sacro-iliac joint in childhood and adolescence is wider, its margins are naturally serrated and lack articular cortex. Features of the adult type of joint generally appear between the ages of 17 and 20 years. Then the joint space will be less wide, its margins will lose their serrations and an articular cortex will appear manifested radiographically by a white line.

Ankylosing spondylitis or, for that matter, any inflammatory lesion of an adult sacro-iliac joint will cause loss of articular cortex and marginal erosions. Thus the pathological adult sacro-iliac joint will resemble the healthy adolescent joint. Rolleston (1947) has described early changes of ankylosing spondylitis as 'a patchy persistence of the adolescent features of the normal joint, seen in adult life when such appearances would not normally be expected'. Useful as is this concept of the changes of early ankylosing spondylitis in the adult, it is obviously of no help in the diagnosis of early changes in the child or adolescent. It is thus clear that it will be necessary for more advanced changes to be reached before a radiological diagnosis is possible under such circumstances. These later changes would take the form of larger subcortical erosions causing a definite widening of joint space and patchy, mottled amorphous peri-articular sclerosis.

It should be mentioned that local osteoporosis round involved joints does occur. However, it is impossible to be certain of this sign since its radiographic appearances are so indefinite. West (1949) emphasized that such terms as 'lack of definition, haziness and ground glass appearance of the sacro-iliac joints' are of no diagnostic aid and indeed such features may be apparent in the healthy subject. The same difficulties apply to the detection of early spinal changes. Erosions of intervertebral, costo-vertebral and costo-transverse joints may appear relatively early in the disease, but their radiographic demonstration may prove impossible. In practice not until changes in the shape of vertebral bodies occur, i.e. squaring and ligamentous ossification, will it be possible to be certain that the spine is involved.

The most useful early sign of ankylosing spondylitis in a young patient is the presence of periarticular sclerosis. Unfortunately sclerosis round sacro-iliac joints may be found in conditions other than ankylosing spondylitis. Not infrequently it is seen for no apparent cause and there is a tendency to overlook it, as in Case 1. Anomalies of the lumbo-sacral spine may be associated with sclerosis round one or both sacro-iliac joints, due presumably to reaction to abnormal stresses and strains. Case 2 had a partially sacralized 5th lumbar vertebra, and the sclerosis round the sacro-iliac joints was originally incorrectly regarded as being secondary to the lumbo-sacral anomaly.

Adolescent osteochondritis provides a further differential diagnosis. This condition may be associated with the presence of sclerosis round the sacro-iliac joints. In this lesion, however, clinical and radiological findings in the spine, usually in the mid- and lower-dorsal regions, are characteristic, and diagnostic difficulties are not to be expected.

The rare type of ankylosing spondylitis presenting as a unilateral sacro-iliitis will need to be differentiated from pyogenic and tuberculous lesions. These latter conditions pursue a more rapid clinical and radiological course and confusion should not occur. Admittedly, Case 3 was incorrectly diagnosed as tuberculosis of a sacro-iliac joint originally. The error was attributable to unawareness at the time that ankylosing spondylitis could present itself unilaterally and in a girl of only 15 years.

\section{Conclusions}

Many children complain of fleeting pains in the lower part of the back and in the hips. Potential causes of such symptoms are many and varied; only a very few of such children eventually develop ankylosing spondylitis. Thus the possibility of the onset of the disease must be kept in perspective. The fact that a few of these children may develop ankylosing spondylitis is important. It is suggested that a prolonged follow-up is indicated in a child giving such a history. The natural tendency is to discharge the patient as cured when the latent period is reached.

Furthermore, it is suggested that a radiograph of the sacro-iliac joints should be taken before the 
child begins training for a career. All three patients reported began in jobs unsuitable for a sufferer from ankylosing spondylitis. One was a nurse, another a shop assistant and the third a butcher.

Difficulties in making the early diagnosis of early ankylosing spondylitis have been discussed. It is felt that the condition can be diagnosed in some cases if it is suspected. Full appreciation of the possibility of the pre-spondylitic phase of the disease is essential. Likewise the radiologist should consider the diagnosis when he sees slightest departures from normal in the sacro-iliac joints. A definitive diagnosis in some will be impossible since no abnormal radiographic changes may be present.

\section{Summary}

Three cases of ankylosing spondylitis are reported in whom symptoms began at the ages of 10,11 and 15 years. Two of these patients were girls.

The importance of recognition of the 'pre- spondylitic syndrome' of ankylosing spondylitis is stressed.

Difficulties in diagnosis of the condition in its early stages are discussed.

It is suggested that if the possibility of the condition is borne in mind and heed is taken of the slightest radiological changes in the sacro-iliac joints, the diagnosis will be made more frequently in childhood.

It is a pleasure to thank my surgical colleagues, Mr. F. G. Allan and Mr. T. S. Donovan, for kindly allowing me access to their case records.

\section{REFERENCES}

Ansell, B. M. and Bywaters, E. G. L. (1962). Diagnosis of 'probable' Still's disease and its outcome. Ann, rheum. Dis., 21, 253.

Edström, G Thune, S and Wittbom-Cigén, G. (1960). Juvenile ankylosing spondylitis. Acta rheum. scand, 6, 161 .

Grainger, R G (1957) Radiological aspects of sacro-iliac arthritis. Proc, roy. Soc. Med , 50, 854 .

Hart, F. D. (1955). Ankylosing spondylitis: A review of 184 cases. Ann. rheum. Dis., 14, 77.

Rolleston, G. L. (1947). The early radiological diagnosis of ankylosing spondylitis. Brit. J. Radiol., $20,288$.

Scott, S. G. (1942). Adolescent Spondylitis or Ankylosing Spondylitis. Oxford University Press, London.

West, H. F. (1949). The aetiology of ankylosing spondylitis. Ann. rheum. Dis., 8, 143. 